\title{
Research on American English Translation of Chinese Signs in Baoding from the Perspective of Cultural Differences
}

\author{
Nan Zhao', Ruixian $\mathrm{Ma}^{2}$, Xiaomei Du${ }^{1}$ \\ ${ }^{1}$ Department of Foreign Languages, Baoding University, Baoding, China \\ ${ }^{2}$ Department of Foreign Language, Hebei Finance University, Baoding, China \\ Email: ckaren2006@126.com
}

Received 2 January 2015; accepted 24 January 2015; published 27 January 2015

Copyright (C) 2015 by authors and Scientific Research Publishing Inc.

This work is licensed under the Creative Commons Attribution International License (CC BY). http://creativecommons.org/licenses/by/4.0/

(c) (7) Open Access

\begin{abstract}
This thesis aims at analyzing the American English translation of Chinese signs in Baoding from the perspective of cultural differences. The thesis researches on signs translation from a new angle by separating American English translation from British English translation and puts special emphasis on American English signs translation, which may be helpful to the standardization of signs translation in China. Through digging out the cultural differences from different thinking mode, value, and usage of the words, the author tries to show how to make the translation purer and tries to revise the translation.
\end{abstract}

\section{Keywords}

Signs, American English Translation, Culture

\section{Introduction}

The research on translation of signs has been attached importance to during recent years. Some heated discussions also appear on the website and mediums. For example, China Daily has launched a movement of error correction of signs which set off an upsurge of learning English. Some provinces have established signs translation committee for doing research on signs translation. And some provinces like Zhejiang and Shanxi have published “Guidelines for English translation in public places”. This translation field was brought into focus. Many experts have shown their different opinions in essays, books or on websites.

Some people discuss signs translation from cultural aspect. For example, Xinyuan Fan points out that "Certain thinking mode and cultural customs come into being under certain cultures, which have great impact on the 
translation of signs" (Fan, 2014). Hong Li shows the idea in "On the Way of Showing Chinese Cultural Characters in Chinese Signs Translation" (Li, 2014). Nan Zhao expresses her viewpoint in "Research on Culture Communication and Signs Translation” (Zhao, 2010). And Jin Xie talks about signs translation from the aspect of pragmatic in "Cross-Cultural Pragmatic Failure-on Signs Translation” (Xie, 2010). Besides, many scholars also have done research from other aspects. Shu Xiao does the research under the guidance of skopos theory in "Mis-translation of Signs in Hainan from the aspect of Skopos theory" (Xiao, 2014). Tingshu Hu and Zhongli Yu use domestication and foreignization method to analyze signs translation (Hu \& Yu, 2012). And Huiqun Yang publishes the article with the name of "On the Characteristics of Signs Translation of the times and the Translation Strategy” (Yang, 2014).

However, the author hasn't found many essays discussing signs translation from the aspect of using American English or British English which may be considered as a new field of research.

And nowadays, errors of signs translation can still be seen in many places. Due to the special and different characters of the two languages, the development of Chinese and English as well as the consecutive changing of signs, signs translation also needs to be revised and changed.

There are many bilingual signs in Baoding which are not unified in style. The standardization of American English translation of Chinese signs will be beneficial to purifing language environment. Through the analysis of signs translation in Baoding, the thesis tries to find suitable way of American English translation of Chinese signs by exploring cultural differences between China and America.

\section{Cultural Differences and American English Translation of Chinese Signs}

Language and culture are closely related to each other. Language can reflect history, geography, religion, and civilization of a country. How to reflect the original culture of a country in the language of another is a difficult task of translation, which causes difficulties for the translation of signs.

Beside the reflection of cultural characteristics, translators should take cultural differences into consideration during the translation of signs. The task-taking team of the research on the standardization of American English translation of Chinese signs in Baoding has found many problems in signs translation, such as grammatical mistakes, spelling mistakes and unclear conveying of culture and so on. And cultural issue is the common existing problem. Due to different ways of thinking, special sense of humor as well as diverse cultures, it's common that equivalent words always couldn't be found during the translation, which has great influence on the spread of culture. During the American English translation of Chinese Signs, the translator should consider more of the cultural differences and culture integration between the two countries, trying to make the translation as exact as possible.

\subsection{Different Thinking Mode in the American English Translation of Signs}

"It is true that the particular structures of a language (sounds, lexemes, syntax, and discourse patterns) may reflect to a certain degree the way people think and they may be said to form 'the ruts or paths for thinking', ... Languages are too open-ended and human imagination is too creative to ever be rigidly ruled by the regulations of syntax or of any other feature of language.” (Nida, 2001).

Different thinking mode is the source of as well as a kind of reflection of cultural differences. Due to this difference, English and Chinese tend to put important information in different positions. Chinese attaches importance to the theme, while English attaches importance to the subject. Thus, during the process of C-E translation, translators may put the important information on the position of the subject, which suits to the American way of thinking.

For example, in Quansheng Valley, a sign has been translated as, "Do Not Benear The Edge Of a Cliff Caution". Due to different ways of expression, Chinese accustomed to put the important information in the end, but English way of expression accustomed to show the important information at the beginning. Therefore, the word "Caution" should be moved to the beginning of the sentence to highlight the theme. According to the writing specifications, function words needn't to be capitalized, so the words like "not", "the” and "of" needn't to be capitalized. Besides, "be” and "near" are two single words, which shouldn't be linked together and may cause confusion. Even if putting a space between the two words, the translation still seems like Chinese English and doesn't suit to the American way of thinking. And considering that American advocates conciseness, the author tries to revise it like this: "Caution! Keep off the cliff edge!”. 


\subsection{Reflection of Individual Value in the American English Translation of Signs}

The American culture put people first which has been shown in many proverbs, such as:

Judge not of man and things at first sight.

He that travels far knows much.

Fortune favors those who use their judgment.

He is rich that has few wants.

Fortune favors the brave.

A man is known by his friends.

Pardon all men, but never thyself.

Translators should keep this in mind during the process of translation. Take the following sign in BEIYUE Temple in Quyang as an example.

The Chinese version has been translated into "Raises hand to make environmental protection the world to be happier". On one hand, "Raises hand” should be "Raise hand” which is grammatically wrong and "to make environmental protection the world" is another grammatical mistake. On the other hand, in order to highlight individual value, the author tries to use parallel structure and translate it into: "Raise our hands, protect our environment, beautify our word!”

\subsection{The Use of Pinyin Doesn’t Suit to Every Situation to Show the Associate Meaning}

For example, in Baili Gorge group in Laishui, Baoding, many signs have been translated in Pinyin, which could not show the original cultural connotation. "HAI TANG YU” is an example. "HAI TANG” is a kind of flower that suits both refined and popular tastes. It enjoys a high renown in China and often appears in Chinese poems and paintings.

In Baili Gorge group, begonias can be seen everywhere, which are tender and charming and with a beautiful legend, they make the gorge gorgeously wonderful! However, the use of Pinyin "HAI TANG YU” here cannot convey the meaning of the Chinese characters and may make the foreigners confused. The word "HAI TANG" can be translated in different ways like "begonia" and "Chinese flowering crab-apple". "HAI TANG" in this scenic spot refers to begonia. "YU” means valley or gorge. Since "YU” here refers to the space among cliffs, the word "gorge" is better. Thus the author tries to translate the name of one of its scenic spots "HAI TANG YU" into "BEGONIA GORGE". Although the word "begonia” still couldn't transfer all the cultural connotation of the Chinese characters, it can show the exact meaning of the word. Through sensuous association and in-site visiting, with some knowledge of Chinese culture and creative thinking, the foreign visitors may understand the words which is good for the spread of culture. Pinyin cannot reach this effect in this situation.

There is another example in Baoding, Hebei Province. In the Botanic Garden, the author has seen three kinds of translation of "toilet” including “Toilet, TOILETS, and Gonggong Weishengjian”. The third translation couldn't be understood by those who don't understand Pinyin. The word "Toilet” can convey the correct meaning, but from the American English Translation of Signs, "Bathroom” or "Restroom” is better for the unification of language.

And three kinds of translation appear in the same place with different writing standards in grammar and form also shows the lack of standardization.

\subsection{Simplicity Should Be Concerned in the Translation}

American English prefers simplicity and some mute letters are deleted in the word. Thus for the unification of style, simple words like "kilogram" should be adopted instead of "kilogramme". Besides, simple sentences are also preferred. For example, in Yugudong Scienic Spot in Baoding, a sign has been translated into "Cars whose owner did not pay the parking fee are not under protection”. The attributive clause makes the sentence lengthy. The visitors prefer appreciating the beautiful scene to reading the signs. Simple sentences are easier to understand. Thus the author tries to revise the translation into "Parking cars without paying are not under protection".

\subsection{Different Way of Spelling in the American English Translation of Chinese Signs}

With the development of American English, the spelling of some words has changed. In BEIYUE Temple, a 
sign translation is as follows:

"The Visitor Center

Services of the Visitor Center:

1. Resting Place for Visitors

......

5. Leaving Luggage”

The word "center" is the American way of expression instead of the English expression of "centre". The use of "Leaving Luggage" is grammatically wrong and for the unification of language in American way, "luggage" can be changed into "baggage". The author tries to translate it into "Baggage Deposit".

\subsection{Spelling Mistakes and Culture Misunderstandings Should Be Avoided in the American English Translation of Chinese Signs}

Due to some spelling mistakes, some translation of signs not only convey the meaning wrongly, but also cause cultural misunderstandings, which may make people confused and even cause serious problems. There's a sign board in "Dong Wuyao Cun" (a village in Baoding) that has been translated into: "DOG WU YAO". The translator translated "Dong" (The Chinese character means "East") into "DOG" (a kind of animal). Although the village has another nickname "Bei Goutou" which contains the character of "dog", yet the use of "DOG" in the translation of the sign may cause misunderstanding among target text readers. Does this village has lots of dogs? Obviously, that's not what the sign means. "Gou" in "Bei Goutou" just refers to the ditch but sounds similar to "dog" in Pinyin. Besides, the use of Pinyin couldn’t clearly transfer the original meaning of the name of the place. Since it is a village, the translation of "East Wu Yao Village" may help people understand it.

\section{Conclusion}

During the process of the American English Translation of Chinese Signs, translators should concern about different thinking mode between American and Chinese, the embodiment of individual value in American culture, different spelling system between American and British English and try to be brief. Translators shouldn't use Pinyin everywhere without the analysis of different situations and try to be creative in the translation to enhance the fusion of Chinese and Western culture.

\section{Acknowledgements}

Sincere appreciation must be given to all that have given their support to the research. This paper is the research result of the Standardization Research on American English Translation of Chinese Signs in Baoding which belongs to the Philosophy and Social Science Planning Projects of Baoding (Project No. 201301213).

The thesis is the research result of Research on the Current Situation and Translation of Publicity materials in Hebei Province with the Aim of Constructing a Strong Province of Great Culture which belongs to the Social Science Fund Project in Hebei Province (Project No. HB14YY034).

It is also the research result of Research on Standardization of Signs Translation and Improvement of Human Environment in Baoding which belongs to the Scientific Research Fund Projects (Social Science) of Baoding University. (Project No. 2011S06).

So special thanks are for Baoding University with her generous support academically and financially.

\section{References}

Fan, X. Y. (2014). On Signs Translation from Cross-Cultural Communication Aspect. Crazy English Teachers, 1, 179.

Hu, T. S., \& Yu, Z. L. (2012). On C-E Signs Translation with the Strategy of Domestication and Foreginization. Journal of Changchun University of Science and Technology (Social Sciences Edition), 1, 87-89.

Li, H. (2014). Science \& Technology Vision. 195.

Nida, E. A. (2001). Language and Culture-Contexts in Translating. Shanghai: Shanghai Foreign Language Education Press.

Xiao, S. (2014). Mis-Translation of Signs in Hainan from the Aspect of Skopos theory. Humanities \& Social Sciences Journal of Hainan University, 5, 121-125. 
Xie, J. (2010). Cross-Cultural Pragmatic Failure-On Signs Translation. Youth Literator.

Yang, H. Q. (2014). On the Characteristics of Signs Translation of the Times and the Translation Strategy. Journal of Jiangsu Second Normal University (Social Science), 7, 105-106.

Zhao, N., Shen, B. G., \& Wang, Z. L. (2010). Research on Culture Communication and Signs Translation. Writer Magazine, 6, 184-185. 
Scientific Research Publishing (SCIRP) is one of the largest Open Access journal publishers. It is currently publishing more than 200 open access, online, peer-reviewed journals covering a wide range of academic disciplines. SCIRP serves the worldwide academic communities and contributes to the progress and application of science with its publication.

Other selected journals from SCIRP are listed as below. Submit your manuscript to us via either submit@scirp.org or Online Submission Portal.
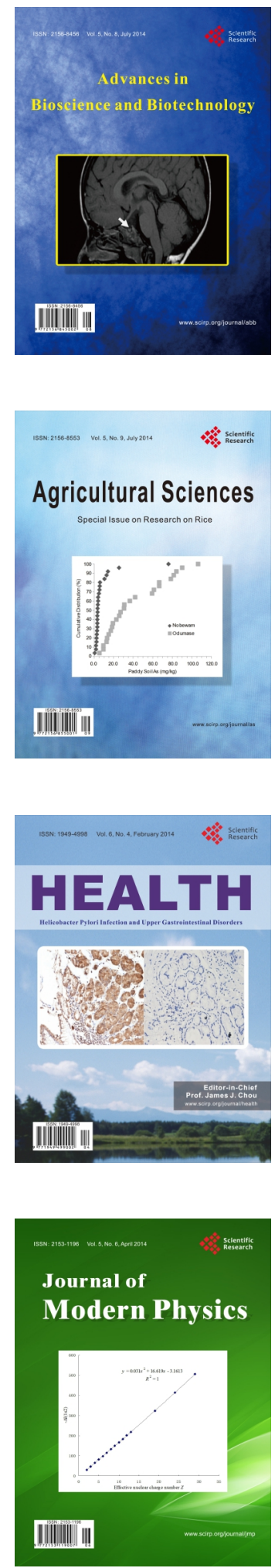
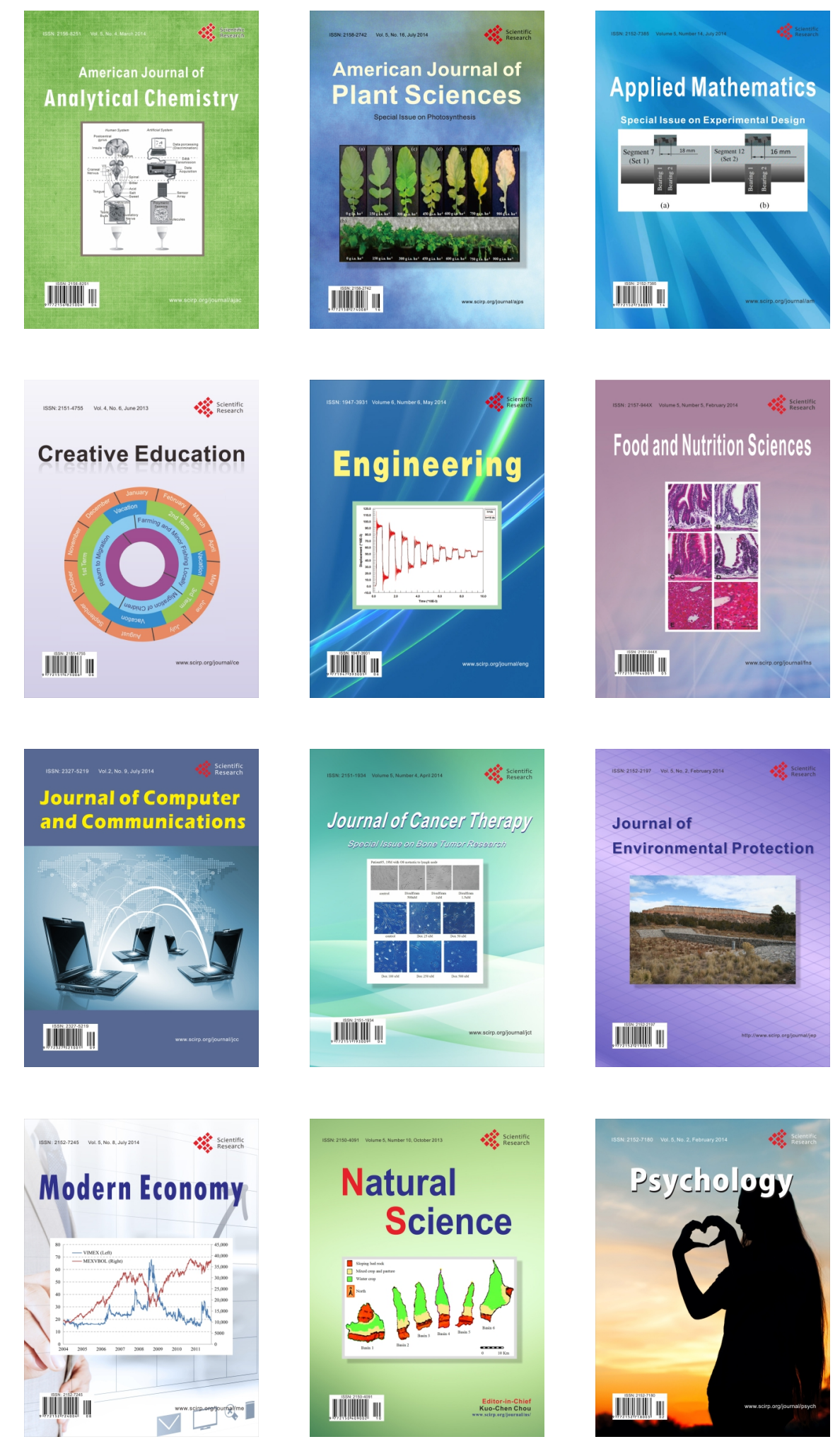